\title{
Self management for men with lower urinary tract symptoms: randomised controlled trial
}

\author{
Christian T Brown, ${ }^{1}$ Tet Yap, ${ }^{1}$ David A Cromwell, ${ }^{2}$ Lorna Rixon, ${ }^{3}$ Liz Steed, ${ }^{3}$ Kathleen Mulligan, ${ }^{3}$ Anthony \\ Mundy, ${ }^{4}$ Stanton P Newman, ${ }^{3}$ Jan van der Meulen, ${ }^{2}$ Mark Emberton ${ }^{4}$
}

\section{EDITORIALP2}

Clinical Effectiveness Unit, Royal College of Surgeons of England, London WC2A 3PE

${ }^{2}$ Health Services Research Unit, London School of Hygiene and Tropical Medicine, London WC1E $7 \mathrm{HT}$

3Unit of Health Psychology, Centre for Behavioural and Social Sciences in Medicine, University College

London

${ }^{4}$ Institute of Urology, University College London, London W1W 7EY Correspondence to: J van der Meulen Jan.vanderMeulen@ LSHTM.ac.uk

BMJ 2007;334:25-8 doi=10.1136/bmj.39010.551319.AE

This is the abridged version of an article that was published on bmj. com on 21 November 2006. Cite this version as BMJ 21 November 2006, doi: http://bmj.com/cgi/ doi/10.1136/bmj.39010.551319. $\mathrm{AE}$ (abridged text, in print: $\mathrm{BM}$ ) 2007;334:25-8)

\section{ABSTRACT}

Objective To evaluate the effectiveness of self management as a first line intervention for men with lower urinary tract symptoms.

Design Randomised controlled trial.

Setting A teaching hospital and a district general hospital in London.

Participants 140 men (mean age 63 (SD 10.7) years), recruited between January 2003 and April 2004, referred by general practitioners to urological outpatient departments with uncomplicated lower urinary tract symptoms. Interventions Self management and standard care $(n=73)$ or standard care alone $(n=67)$. The self management group took part in three small group sessions comprising education, lifestyle advice, and training in problem solving and goal setting skills.

Main outcome measures The primary outcome measure was treatment failure measured at 3, 6, and 12 months. Symptom severity (international prostate symptom score; higher scores represent a poorer outcome) was used as a secondary outcome.

Results At three months, treatment failure had occurred in $7(10 \%)$ of the self management group and in 27 (42\%) of the standard care group (difference $=32 \%, 95 \%$ confidence interval $18 \%$ to $46 \%$ ). Corresponding differences in the frequency of treatment failure were $42 \%$ (27\% to $57 \%$ ) at six months and $48 \%(32 \%$ to $64 \%$ ) at 12 months. At three months, the mean international prostate symptom score was 10.7 in the self management group and 16.4 in the standard care group (difference $=5.7,3.7$ to 7.7). Corresponding differences in score were 6.5 (4.3 to 8.7) at six months and 5.1 (2.7 to 7.6 ) at 12 months.

Conclusions Self management significantly reduced the frequency of treatment failure and reduced urinary symptoms. Because of the large observed benefit of self management, the results of this study support the case for a large multicentre trial to confirm whether self management could be considered as first line treatment for men with lower urinary tract symptoms.

Trial registration National Research Register N0263115137; Clinical trials NCT00270309.

\section{INTRODUCTION}

Standard care for men with lower urinary tract symptoms has developed into a "cascade" that escalates from "watchful waiting" through a variety of drugs to surgery. ${ }^{12}$ Healthcare professionals involved in the care of men with lower urinary tract symptoms routinely advise lifestyle modifications. However, the type of advice given varies considerably. ${ }^{3} \mathrm{~A}$ formal consensus development exercise was carried out to define the lifestyle modifications that are likely to be effective in improving lower urinary tract symptoms. ${ }^{4}$

We developed a self management intervention for men with lower urinary tract symptoms that incorporated the recommendations of the consensus panel. ${ }^{4}$ The purpose of the programme was to reduce urinary symptoms and to delay or avoid an escalation in treatment. We did a randomised controlled trial in two centres to compare men with lower urinary tract symptoms who participated in a self management programme in addition to standard care with those who received standard care alone.

\section{METHODS}

Patient population-We recruited men with uncomplicated lower urinary tract symptoms from the outpatient departments of two urological centres in London. We randomised the men either to attend a self management programme in addition to standard care or to standard care alone. All patients aged over 40 with lower urinary tract symptoms who were referred for the first time by their general practitioner were eligible for inclusion. We excluded some men on the basis of drug treatment, recent surgery, complications potentially related to their symptoms, or severe comorbidity.

Standard care-Standard care in the two participating centres began with watchful waiting. Escalation to medical treatment and surgery was left to the discretion of the clinician and patient.

Intervention - In addition to standard care, the intervention group took part in small group sessions (five to eight men), each lasting between 1.5 and 2 hours, which were scheduled one, two, and six weeks after randomisation. The aim of these sessions was to bring about modification of lifestyle (fluid management, avoidance of caffeine, and use of alcohol) and specific changes in behaviour (bladder retraining, double voiding, and urethral milking). (See appendix on bmj.com and reference 5 for a description of the information component.) We designed the sessions to enable the participants to learn techniques of problem solving 
and goal setting. At 3, 6, and 12 months, clinicians who were not involved in the conduct of the trial saw participants in the urology outpatient departments.

Outcomes-The primary outcome was treatment failure (rise of 3 points or more on the international prostate symptom score, use of drugs to control lower urinary tract symptoms, acute urinary retention, or surgical intervention) during follow-up. ${ }^{56}$ Secondary outcomes included severity of symptoms (international prostate symptom score), troublesomeness of symptoms (benign prostatic hypertrophy impact index), and disease specific quality of life (American Urological Association quality of life score)..$^{5}$

Statistical analysis-We analysed outcomes at 3, 6, and 12 months separately on an intention to treat basis. We did regression to adjust comparisons for potential imbalances in the baseline characteristics of the two groups (age, severity of symptoms, duration of symptoms, level of education, and number of comorbidities).

\section{RESULTS}

Of the 186 patients who were eligible for randomisation during the recruitment period, 46 were excluded. Of the 140 men who were included, we randomised 73 to participate in the self management programme and 67 to standard care alone. Compliance with the self management programme was high; $68(93 \%)$ patients attended all three sessions. The five patients who did not attend were included in the self management group for analysis.

\section{Baseline characteristics}

The distributions of the patient demographics in the self management group and the standard care group were broadly similar (see bmj.com). Comorbidity was slightly more frequent in the self management group. Although most patients in the two groups fell in the moderate category of symptom severity, more patients

Table 1 | Primary and secondary outcomes at 3, 6, and 12 months. Values are mean (SD) unless stated otherwise

Self management $(n=73)$

Value No missing Standard care $(n=67)$ Value $\quad \begin{gathered}\text { No } \\ \text { missing }\end{gathered}$ Difference $(95 \% \mathrm{Cl})$

\section{Three month outcomes}

\begin{tabular}{lcccccc}
\hline Treatment failures $(\%(\mathrm{No}))$ & $10(7)$ & 2 & $42(27)$ & 2 & $32(18$ to 46$)$ & $<0.001$ \\
\hline IPSS & $10.7(5.9)$ & 2 & $16.4(5.8)$ & 3 & $5.7(3.7$ to 7.7$)$ & $<0.001$ \\
\hline BPH impact index & $3.3(2.8)$ & 2 & $4.7(2.6)$ & 3 & $1.4(0.5$ to 2.3$)$ & 0.003 \\
\hline AUA-QoL score & $2.8(1.2)$ & 2 & $3.4(1.1)$ & 3 & $0.7(0.3$ to 1.1$)$ & $<0.001$
\end{tabular}

\section{Six month outcomes}

\begin{tabular}{lllllll}
\hline Treatment failures (\% (No)) & $19(13)$ & 4 & $61(39)$ & 3 & $42(27$ to 57$)$ & $<0.001$ \\
\hline
\end{tabular}

\begin{tabular}{lllllll}
\hline IPSS & $10.4(6.1)$ & 6 & $16.9(6.4)$ & 6 & $6.5(4.3$ to 8.7$)$ & $<0.001$ \\
\hline
\end{tabular}

\begin{tabular}{lllllll}
\hline BPH impact index & $3.5(2.9)$ & 7 & $4.8(2.8)$ & 6 & $1.4(0.4$ to 2.4$)$ & 0.008 \\
\hline AUA-OoL score & $2.6(1.3)$ & 6 & $3.3(1.4)$ & 6 & $0.6(0.2$ to 1.1$)$ & 0.008
\end{tabular}

\section{Twelve month outcomes}

Treatment failures (\% (No))

IPSS

BPH impact index

(18)

AUA-QoL score

$10.2(6.1)$

$14 \quad 79(44)$

11

$48(32$ to 64$)$

$3.0(3.3)$

18

$15.4(6.6)$

11

$48(32$ to 64$)<0.001$

19

4.3 (2.9)

16

5.1 (2.7 to 7.6$)$

$1.2(0$ to 2.4$)$
$0.5(0$ to 1.0$)$

$<0.001$

AUA-OoL=American Urological Association quality of life; $\mathrm{BPH}=$ benign prostatic hypertrophy; IPSS=international prostate symptom score. in the standard care group had either mild or severe symptoms.

\section{Primary outcome}

At 3, 6, and 12 months, treatment failure was considerably more frequent in patients who were randomised to standard care alone than in those randomised to self management (table 1). The principal reasons for failure were prescription of $\alpha$ blockers or a rise in international prostate symptom score (table 2). Adjustment for baseline characteristics did not change these results.

The results in table 1 represent only patients with complete information at 3,6 , and 12 months. When we imputed missing values by using results of the previous measurements, only small changes occurred in the differences between the two groups and these differences remained statistically significant.

\section{Secondary outcomes}

At 3, 6, and 12 months, patients who were randomised to self management had less severe symptoms than patients randomised to standard care alone (table 1). The differences in international prostate symptom score increased slightly when we adjusted them for baseline characteristics. Patients who were randomised to self management were also less troubled by their symptoms and had a better quality of life than patients who were randomised to standard care alone (table 1). When we imputed missing values by using results of the previous measurements, the differences in symptom severity, troublesomeness, and quality of life remained statistically significant at 3,6 , and 12 months.

\section{DISCUSSION}

Self management in addition to standard care significantly reduced the rate of treatment failure and improved urinary symptoms, compared with standard care alone. The difference in symptoms between the treatment groups is twice as large as that seen when medical treatment is compared with placebo. ${ }^{1}$ The benefits of self management were seen early and were sustained at six and 12 months.

\section{Methodological considerations}

The treatment of men in the standard care group may have been contaminated because of the conduct of the trial. This contamination, which would have reduced the difference between the groups, may have occurred through changes in the advice the clinicians gave to their patients or through direct communication between patients allocated to different groups. However, the crucial difference between the two treatment groups is the problem solving and goal setting skills that patients acquired as a result of attending the programme. These skills are unlikely to have been conferred during the clinical consultation or transferred from one patient to another.

Lack of blinding of patients to the treatment allocation is another source of bias. However, we asked patients not to reveal their allocation to the clinicians 
Table 2 | Reasons for treatment failure at 3, 6, and 12 months. Values are numbers of patients

\begin{tabular}{|c|c|c|}
\hline & $\begin{array}{c}\text { Self } \\
\text { management }\end{array}$ & Standard care \\
\hline Treatment failures at three months & 7 & 27 \\
\hline \multicolumn{3}{|l|}{$\begin{array}{l}\text { Reasons for treatment failures at three } \\
\text { months: }\end{array}$} \\
\hline$\alpha$ blocker & 3 & 12 \\
\hline Finasteride & 0 & 0 \\
\hline Anticholinergic & 1 & 1 \\
\hline Surgery & 1 & 1 \\
\hline $\begin{array}{l}\text { Catheterised for acute urinary } \\
\text { retention }\end{array}$ & 0 & 2 \\
\hline Other drug treatment & 0 & 0 \\
\hline Rise in IPSS of $\geq 3$ points & 4 & 20 \\
\hline Treatment failures at six months & 13 & 39 \\
\hline
\end{tabular}

Reasons for failures between three and

six months:

\begin{tabular}{lcc}
\hline$\alpha$ blocker & 0 & 4 \\
\hline Finasteride & 0 & 1 \\
\hline Anticholinergic & 3 & 0 \\
\hline Surgery & 0 & 0 \\
\hline $\begin{array}{l}\text { Catheterised for acute urinary } \\
\text { retention }\end{array}$ & 0 & 0 \\
\hline $\begin{array}{l}\text { Other drug treatment } \\
\text { Rise in IPSS of } \geq 3 \text { points }\end{array}$ & 0 & 1 \\
\hline $\begin{array}{l}\text { Treatment failures at 12 months } \\
\text { Reasons for failures between six and }\end{array}$ & 3 & 6 \\
\hline
\end{tabular}

Reasons for failures between six and

12 months:

\begin{tabular}{lll}
\hline$\alpha$ blocker & 3 & $2^{*}$ \\
\hline Finasteride & 1 & 0 \\
\hline Anticholinergic & 0 & 0 \\
\hline Surgery & 0 & 0 \\
\hline $\begin{array}{l}\text { Catheterised for acute urinary } \\
\text { retention }\end{array}$ & 0 & 0 \\
\hline $\begin{array}{l}\text { Other drug treatment } \\
\text { Rise in IPSS of } \geq 3 \text { points }\end{array}$ & 0 & 0 \\
\hline
\end{tabular}

IPSS=international prostate symptom score.

${ }^{\star}$ One patient was prescribed an $\alpha$ blocker and had a rise in IPSS of $\geq 3$ points.

doing the consultations after randomisation. The effect of this lack of blinding would be small because the self management programme was carried out only during the first six weeks and the first clinical visit took place at least six weeks after the last session of the programme. By that time, the severity of symptoms expressed by patients will have determined treatment decisions rather than the clinician's awareness of whether a patient had participated in the self management programme.

\section{WHAT IS ALREADY KNOWN ON THIS TOPIC}

Standard treatment for men with lower urinary tract symptoms has developed into a "cascade" that starts with watchful waiting and moves up to drugs and surgery

Self management interventions that aim to enhance patients' problem solving and goal setting skills have been shown to be an effective treatment for arthritis, diabetes, and asthma.

\section{WHAT THIS STUDY ADDS}

Self management was at least as effective as medical treatment for men with uncomplicated lower urinary tract symptoms

\section{Explanations for observed results}

Our study indicates that self management may be a very effective treatment for men with lower urinary tract symptoms. A possible explanation is that the influences of lifestyle modification for lower urinary tract symptoms are immediately apparent to patients, in contrast to the delayed effects associated with lifestyle modifications for other chronic diseases. This immediacy of effect provides positive feedback. Furthermore, patients can try out the effects of the different lifestyle modifications and adapt them according to their individual circumstances.

Severity of symptoms in the standard care group remained more or less the same compared with baseline. This apparent lack of effect of standard care in our study contributes to the large difference in symptom severity between the two treatment groups. We would have expected an improvement in symptoms with standard care either through "regression to the mean" or as a result of some of the men being offered medical or surgical treatment. However, the impact of regression to the mean is likely to be small. Symptom severity was not one of the inclusion criteria, and the time interval between referral and recruitment was long (four to six months) and variable, which will have diminished the link between severity of symptoms at the time of referral and at the time of recruitment. Furthermore, only about $20 \%$ of the men who received standard care alone were given medical or surgical treatment, and the rest remained untreated.

A multicentre pragmatic randomised controlled trial should now be carried out to determine whether our results can be replicated in everyday clinical practice. ${ }^{8}$

\section{Conclusion}

The results from this small two centre study are sufficiently impressive that a policy of self management as described in this paper has the potential to become the ideal first line treatment for men with uncomplicated lower urinary tract symptoms, provided that further studies show their generalisability. The only imaginable harm that can result from self management is that for some patients medical or surgical treatment is postponed.

We thank all the men who agreed to take part in this trial. We also acknowledge the work of Jane Coe and Daphne Colpman, urology nurse specialists, University College London Hospitals NHS Foundation Trust, for acting as facilitators to the self management groups.

\section{Contributors: See bmj.com}

Funding: BUPA Foundation Project Grant. CTB received a research fellowship from the Royal College of Surgeons of England, funded by Cazenove \& Co. JvdM is funded by a national public health career scientist award from the Department of Health and NHS R\&D Programme.

Competing interests: ME has received fees from GlaxoSmithKline and Sanofi-Synthelabo for acting as a consultant, giving lectures, and working as an investigator. All other authors: none declared.

Ethical approval: Medical research ethics committees of the participating hospitals.

1 American Urological Association. Guidelines on the management of benign prostatic hyperplasia. 2003. www.auanet.org/guidelines/ bph.cfm (accessed 15 Dec 2005). 
2 Madersbacher S, Alivizatos G, Nordling J, Rioja Sanz C, Emberton M, De la Rosette JJMCH. EAU 2004 guidelines on assessment, therapy and follow-up of men with lower urinary tract symptoms suggestive of benign prostatic hyperplasia (BPH guidelines). Eur Urol 2004;46:547-54.

3 Brown CT, Van der Meulen J, Mundy AR, Emberton M. Lifestyle and behavioural interventions for men on watchful waiting with uncomplicated lower urinary tract symptoms: a national multidisciplinary survey. BJU Int 2003:92:53-7.

4 Brown CT, Van der Meulen J, Mundy AR, O’Flynn E, Emberton M. Defining the components of a self-management programme for men with uncomplicated lower urinary tract symptoms: a consensus approach. Eur Urol 2004;46:254-63.

5 Barry MJ, Fowler FJ Jr, O’Leary MP, Bruskewitz RC, Holtgrewe HL,
Mebust WK, et al. The American Urological Association symptom index for benign prostatic hyperplasia. J Urol 1992;148:1549-57.

6 Barry MJ, Williford WO, Chang Y, Machi M, Jones KM, Walker-Corkery $\mathrm{E}$, et al. Benign prostatic hyperplasia specific health status measures in clinical research: how much change in the American Urological Association symptom index and the benign prostatic hyperplasia impact index is perceptible to patients? J Urol 1995;154:1770-4.

7 Barry MJ, Fowler FJ Jr, O'Leary MP, Bruskewitz RC, Holtgrewe HL, Mebust WK. Measuring disease-specific health status in men with benign prostatic hyperplasia. Med Care 1995;33:135-45.

8 Campbell M, Fitzpatrick R, Haines A, Kinmonth AL, Sandercock P, Spiegelhalter D, et al. Framework for design and evaluation of complex interventions to improve health. BM/2000;321:694-6. Accepted: 13 October 2006

\title{
Provision of taped conversations with neonatologists to mothers of babies in intensive care: randomised controlled trial
}

\author{
Tieh Hee Hai Guan Koh, ${ }^{1}$ Phyllis N Butow, ${ }^{2}$ Michael Coory, ${ }^{3}$ Donna Budge, ${ }^{4}$ Li-An Collie, ${ }^{4}$ John Whitehall, ${ }^{1}$ \\ Martin H Tattersall ${ }^{5}$
}

\section{EDITORIAL p1}

1'Institute of Women's and

Children's Health, Townsville

Hospital, Douglas, QLD 4814,

Australia, and Medical School of

James Cook University, Douglas,

QLD

${ }^{2}$ Medical Psychology Research

Unit, University of Sydney, NSW

Australia

${ }^{3}$ School of Population Health,

Queensland Health, Brisbane,

Australia

${ }^{4}$ Institute of Women's and

Children's Health, Townsville

Hospital, Douglas

${ }^{5}$ Faculty of Medicine, University of Sydney

Correspondence to: TH H G Koh

guan_koh@health.qld.gov.au

BMJ 2007;334:28-31

doi=10.1136/bmi.39017.675648.BE
This is the abridged version of an article that was posted on bmj. com on 1 December 2006. Cite this version as BMJ 1 December 2006 , doi: 10.1136/bmj.39017.675648. $\mathrm{BE}$ (abridged text, in print: BMJ 2007;334:28-31)

\section{ABSTRACT}

Objective To determine whether providing mothers of babies in neonatal intensive care units with audiotapes of their conversations with a neonatologist improves recall of information and psychological wellbeing.

Design Randomised, single blinded trial.

Setting Neonatal intensive care unit, north Queensland, Australia.

Participants 200 mothers of babies in a neonatal intensive care unit.

Interventions Mothers given ( $\mathrm{n}=102)$ or not given $(\mathrm{n}=98)$ audiotapes of their conversations with a neonatologist. Main outcome measures Recall of information, attitudes to and use of the tape, satisfaction with conversations, postnatal depression, anxiety, general health, and stress about parenting, at 10 days and four and 12 months. Results $91 \%(n=93)$ of mothers in the tape group listened to the tape (once by day 10 , twice by four months, and three times by 12 months; range 1-10). At 10 days and four months, mothers in the tape group recalled significantly more information about diagnosis, treatment, and outcome than mothers in the control group. At four months mothers in the tape group were $75 \%$ more likely to recall all of the information about treatment than mothers in the control group (59\% v $34 \%$; risk ratio 1.75, $95 \%$ confidence interval 1.27 to 2.4). Six mothers, all in the control group, could not recall their conversations. No statistically significant differences were found between the groups in satisfaction with conversations ( 10 days), postnatal depression and anxiety scores (10 days, four and 12 months), and stress about parenting (12 months).

Conclusion Providing the mothers of babies in neonatal intensive care units with audiotapes of conversations with a neonatologist enhanced their recall of information (up to four months). The taped conversations did not affect the mothers' wellbeing or satisfaction with the neonatologist.

Trial registration Australian Clinical Trials Registry 12606000478516.

\section{INTRODUCTION}

Several studies have found that giving adults with cancer an audiotape of their initial conversations with oncologists improved their psychological distress, anxiety, satisfaction with conversations, and recall of information whereas other authors found no benefits. ${ }^{1-7}$ We carried out a randomised single blind trial to compare the effects of providing or not providing mothers of babies in neonatal intensive care units with an audiotape of their conversations with the neonatologist.

\section{METHODS}

Mothers were eligible for the study if their babies were admitted to the neonatal intensive care unit at the Townsville Hospital, the regional neonatal unit for north Queensland (see bmj.com). The study was a randomised controlled trial of audiotape provision, with the neonatal team blinded to allocation. Before the first conversation the mothers completed a questionnaire eliciting personal details, anxiety scores, and preferences for information and involvement in decision making. A randomisation service then allocated the mother to receive or not to receive a tape of their conversations with a neonatologist.

After randomisation the initial conversation and subsequent conversations of significance were taped and analysed. The mothers in the experimental arm received a tape of each of the conversations and a tape recorder.

Ten days and four months after the initial conversation the researcher interviewed the mothers to document their recall of the diagnosis, tests, treatment, and outcome of their babies as conveyed by the neonatologist. Mothers also completed a questionnaire to ascertain views of the taping, use of the tapes, anxiety, general health, depression, marital satisfaction, social support, and satisfaction with conversations held with 